\begin{tabular}{||ll||}
\hline \hline Citation & Maes, M., Vanhalst, J., Spithoven, A. W. M., Van den \\
& $\begin{array}{l}\text { Noortgate, W., \& Goossens, L. (2016). Loneliness and attitudes } \\
\text { toward aloneness in adolescence: A person-centered approach. } \\
\text { Journal of Youth and Adolescence, 45, 547-567. } \\
\text { doi:10.1007/s10964-015-0354-5 }\end{array}$ \\
\hline Archived version & $\begin{array}{l}\text { Author manuscript: the content is identical to the content of the } \\
\text { published paper, but without the final typesetting by the publisher }\end{array}$ \\
\hline Published version & $\underline{\text { http://dx.doi.org/10.1007/s10964-015-0354-5 }}$ \\
\hline Journal homepage & $\underline{\text { http://link.springer.com/article/10.1007\%2Fs10964-015-0354-5 }}$ \\
\hline Author contact & $\underline{\text { www.marliesmaes.com }}$ \\
\hline
\end{tabular}

(article begins on next page) 


\begin{abstract}
In adolescence, feeling lonely and dealing with time spent alone become particularly salient. The present study examined the co-occurrence of parent- and peer-related loneliness, and positive and negative attitudes toward aloneness, using cluster analysis. In three independent samples, covering about 1,800 adolescents ( $61 \%$ female), six meaningful groups were identified. These groups showed different associations with adolescents' self-esteem and personality, parental responsiveness and psychological control, and peer group functioning and friendships. An adaptive pattern of correlates was found for adolescents in three of the six groups, that is, the Indifference group (with rather low scores on the four constructs), the Moderate group (with moderate scores on the four constructs), and the Negative Attitude Toward Aloneness group. A rather maladaptive pattern of correlates was found for adolescents in the three other groups, that is, the Peer-Related Loneliness group, the Positive Attitude Toward Aloneness group, and the Parent-Related Loneliness group. More specifically, adolescents in the Peer-Related Loneliness and Positive Attitude Toward Aloneness groups may need assistance regarding their relations with their peers, whereas adolescents in the Parent-Related Loneliness group may need assistance regarding their relations with their parents. Implications of these findings for current understanding and optimal measurement of adolescents' loneliness and aloneness are discussed.
\end{abstract}

Keywords: loneliness, attitudes toward aloneness, cluster analysis, adolescents, parents, peers 
Loneliness and Attitudes Toward Aloneness in Adolescence: A Person-Centered Approach

Feeling lonely and dealing with time spent alone are experiences that occur throughout the life span. Those experiences, however, become particularly salient in adolescence, when many changes in cognitive abilities and social relationships occur (Qualter et al., 2015; Majorano, Musetti, Brondino, \& Corsano, 2015). Compared to children, adolescents spend an increasing amount of time on their own, and feeling lonely is a common experience in this period of life (Larson, 1997; Long \& Averill, 2003; Qualter et al., 2015). People may feel lonely when alone, but also when they are surrounded by other people. Thus, loneliness is different from aloneness, that is, the objective experience of being without company (Long \& Averill, 2003). More specifically, loneliness is an unpleasant experience that occurs when people perceive their social relations to be deficient, either quantitatively or qualitatively (Hawkley \& Capitanio, 2015; Perlman \& Peplau, 1981). Feelings of loneliness arise to signal to people that there is something missing in their social relationships and to motivate them to reconnect again. According to this evolutionary theory of loneliness (Cacioppo et al., 2015), a person who feels lonely also feels unsafe, and a survival mechanism is activated that heightens sensitivity to threats, which is accompanied by a host of negative feelings, including stress and low self-esteem (Hawkley \& Cacioppo, 2010).

Adolescents may feel lonely in certain relationships (e.g., their parents), but not in others (e.g., their peers), and may have more or less negative or positive attitudes toward aloneness. To examine these relation-specific types of loneliness and attitudes toward aloneness, hybrid multidimensional models have been developed and used in the literature (Goossens et al., 2009; Houghton et al., 2014; Maes, Klimstra, Van den Noortgate, \& Goossens, 2015; Majorano et al., 2015). The different types of loneliness and the different attitudes to aloneness can all be found to a certain degree within each individual, but their co- 
occurrence usually is not investigated as such. This study aims to identify groups of adolescents that share a similar pattern of scores across the different types of loneliness and attitudes toward being alone. In addition, we examine whether some of these groups are more vulnerable than others, in terms of adolescents' self-esteem and personality, parental responsiveness and psychological control, and peer group functioning and friendships.

\section{Loneliness and Aloneness in Adolescence}

Studying loneliness and attitudes toward aloneness is important during adolescence for different reasons. During this phase of life, social experiences change and so do adolescents' expectations about social interactions and their perceptions of what constitutes social isolation (Qualter et al., 2015). During adolescence, especially in Western cultures, the tension between social connection and individuation peaks (Larson, Richards, Moneta, Holmbeck, \& Duckett, 1996). On the one hand, adolescents are expected to conform to the peer group and have close and intimate friends. On the other hand, gaining independence is a central developmental task in this phase of life. Adolescents may struggle to find a balance regarding this issue, which may lead to increased feelings of loneliness. A peak in loneliness has indeed been found in the adolescent years (Qualter et al., 2015). Furthermore, during adolescence, the relationships with parents and peers change. In early adolescence, parents occupy a central position in adolescents' personal network, but this position is gradually taken over by friends (Meeus \& Deković, 1995). This transition, however, does not mean that adolescents do not need parental support anymore and both the parent and peer context remain important to the adolescent. In each relationship, adolescents may or may not feel lonely. That parent- and peer-related loneliness can be distinguished was also suggested by a recent meta-analysis that found a rather small average correlation between these two relation-specific types of loneliness $(r=$ .22; Maes, Van den Noortgate, \& Goossens, 2015). 
Regarding attitudes toward aloneness, positive attitudes may be expected to emerge in adolescence, because time alone might be deliberately used, for example, for emotional selfregulation and identity development (Larson, 1997; Long \& Averill, 2003). Research indeed found an increase in positive attitudes toward aloneness, accompanied by a decrease in negative attitudes from early adolescence onwards (Marcoen \& Goossens, 1993; Marcoen, Goossens, \& Caes, 1987). Positive attitudes toward aloneness, however, may also lead to excessive time alone, which in turn may increase feelings of loneliness when adolescents miss important opportunities for social interactions (Wang, Rubin, Laursen, Booth-LaForce, \& Rose-Krasnor, 2013). Positive and negative attitudes toward aloneness are not two opposite ends of the same continuum, as is confirmed by a recent meta-analysis showing a very small average correlation between the two ( $r=-.02$; Maes, Van den Noortgate et al., 2015).

\section{Correlates of Loneliness and Attitudes Toward Aloneness}

Bronfenbrenner's (1977) ecological model of human development already highlighted that it is important to look not only at adolescents' personal characteristics, but also at the context these adolescents live in. Two key interpersonal contexts for adolescents are the parent and peer contexts. The social needs perspective emphasizes that different social relationships may fulfill different social needs (Sullivan, 1953; Weiss, 1973). Weiss (1973) distinguished different types of provisions that may be offered by different relationships, such as attachment, social integration, reassurance of worth, and guidance. Whereas certain provisions may be offered by adolescents' relationships with both parents and peers (e.g., assurance of worth), other provisions may be offered particularly parent but not by peers (e.g., guidance), or by peers but not by parents (e.g., social integration). Therefore, a lack of certain provisions may result in parent-related loneliness or parent-related loneliness only. In addition, within the peer context, different types of peer relations exist, such as the larger peer group or dyadic friendships, both of which may also meet different needs (Ladd, 
Kochenderfer, \& Coleman, 1997). Taken together, these models suggest that relation-specific types of loneliness are associated with difficulties in different domains. In the present study, therefore, we will associate loneliness and attitudes toward aloneness with adolescents' personal characteristics (i.e., self-esteem and personality), the parental context (i.e., parental responsiveness and psychological control), and the peer context (i.e., peer group functioning and dyadic friendships).

Adolescents' self-esteem and personality. Two classes of personality characteristics can be distinguished (Asendorpf \& Van Aken, 2003). Surface personality characteristics, such as self-esteem, are highly susceptible to environmental influences, whereas core personality characteristics, such as the Big Five, are more immune to these influences. Both surface and core personality characteristics have been found to be related to loneliness and attitudes toward aloneness. In line with the evolutionary theory of loneliness, many studies have found a strong negative relation between self-esteem and loneliness (Mahon, Yarcheski, Yarcheski, Cannella, \& Hanks, 2006; Vanhalst, Luyckx, Scholte, Engels, \& Goossens, 2013). This link between loneliness and social self-esteem is also suggested by the Sociometer Hypothesis (Leary, Tambor, Terdal, \& Downs, 1995), which states that self-esteem functions as a subjective monitor that evaluates the extent to which an individual is included or excluded. Feelings of not being included (c.f., loneliness) are related with lower self-esteem. Research examining specific domains of self-esteem found that loneliness was related with self-esteem in the subdomains of close friendships, romantic appeal, academic performance, and physical appearance (Cheng \& Furnham, 2002; Grøholt, Ekeberg, Wichstrøm, \& Haldorsen, 2005). Whether such associations are more pronounced for parent- or peer-related loneliness is as yet unclear. Regarding attitudes toward aloneness, negative relations with general self-esteem have been found for both negative and positive attitudes to being alone (Teppers, Luyckx, Vanhalst, Klimstra, \& Goossens, 2014). 
The Big Five personality characteristics refer to five major personality traits (Caspi, Roberts, \& Shiner, 2005), including extraversion (i.e., the tendency to engage in social behaviors, and to experience frequent positive moods), agreeableness (i.e., an individual's sociability, empathy, and cooperativeness), conscientiousness (i.e., organizational and motivational aspects of a person's behavior), neuroticism (i.e., the inability to deal with negative emotions, also referred to as the opposite of emotional stability), and openness (i.e., the way an individual seeks for and deals with new information). Although personality characteristics are less closely related with the conceptual definition of loneliness, they have a strong intuitive appeal (Goossens, 2006). Certain personality traits may reduce social attractiveness, influence one's interactional behavior, or affect one's reactions to changes in social relationships (Peplau \& Perlman, 1982). Interestingly, those associations seem to be different for parent- and peer-related loneliness, as well as for positive and negative attitudes toward being alone (Asendorpf \& Van Aken, 2003; Teppers et al., 2013). For example, loneliness in relations with peers, but not parents, was associated with less extraversion and more openness to experience, whereas loneliness in relation with parents, but not peers, was related with lower conscientiousness. Further, lower agreeableness was associated with both peer- and parent-related loneliness (Teppers et al., 2013). Concerning the associations between personality and attitudes toward aloneness, extraversion was associated with less positive and more negative attitudes toward aloneness (Teppers et al., 2013). Negative attitude to being alone was further associated with lower agreeableness and conscientiousness, whereas positive attitudes were associated with lower emotional stability and higher openness to experience (Teppers et al., 2013).

Parental responsiveness and psychological control. Parents constitute an important interpersonal context for adolescents. Both positive (e.g., responsiveness) and negative (e.g., psychological control) parenting behaviors have been associated with loneliness (Mahon et 
al., 2006; Soenens, Vansteenkiste, Goossens, Duriez, \& Niemiec, 2008). Only one study thus far has differentiated between relation-specific types of loneliness. This study, based on selfreports, indicated that acceptance and child-centeredness (c.f., responsiveness) were negatively associated with parent-related loneliness, whereas psychological control was positively related with parent-related loneliness (Scharf, Wiseman, \& Farah, 2011). The same patterns were found for peer-related loneliness, but the strength of the associations was lower. An explanation for these findings, inspired by attachment research (Kochanska \& Kim, 2013; Pallini, Baiocco, Schneider, Madigan, \& Atkinson, 2014), proposes that experiences with parents will give rise to internal working models, which might be generalized by adolescents to their relationships with peers (Cassidy \& Berlin, 1999; Rotenberg, 1999; Scharf et al., 2011). Regarding attitudes toward aloneness, positive and negative attitudes were not related with parenting behaviors, except for a positive relation between psychological control and positive attitudes toward aloneness (Scharf et al., 2011).

Peer group functioning and friendships. In line with the social needs perspective (Sullivan, 1953; Weiss, 1973), loneliness has been associated with different types of peer relationships, including adolescents' functioning in the larger peer group and dyadic friendships (Ladd et al., 1997; Vanhalst, Luyckx, \& Goossens, 2014). Research on the larger peer group, using peer nominations, found that adolescents' loneliness was associated with lower peer acceptance, more peer victimization, and higher levels of shyness, but was unrelated with peer-nominated aggression (Woodhouse, Dykas, \& Cassidy, 2012). When differentiating among relation-specific types of loneliness, peer-, but not parent-, related loneliness has been found to be related with peer group functioning and friendships. For example, peer victimization was only associated with peer-related loneliness (Brighi, Guarini, Melotti, Galli, \& Genta, 2012). Peer-related loneliness was further found to be negatively related with friendship quantity (Bowker \& Spencer, 2010) and quality (Soenens et al., 2008; 
Vanhalst et al., 2014). The only study examining attitudes toward aloneness in the peer context found that negative attitudes were positively related with the quality of adolescents' peer relations (Corsano, Majorano, \& Champretavy, 2006).

\section{The Present Study}

Although the knowledge base on adolescents' loneliness is expanding, studies on adolescents' attitudes toward aloneness are still rather scarce. Moreover, the majority of loneliness studies still adopts a unidimensional approach, while feelings of loneliness are likely relationship-specific. The present study, therefore, focuses on both positive and negative attitudes toward aloneness and on two relation-specific types of loneliness, that is, parent- and peer-related loneliness. Furthermore, most studies have adopted a variablecentered approach and examined how loneliness and attitudes toward aloneness uniquely were related with other variables. However, parent- and peer-related loneliness, and negative and positive attitudes toward aloneness are all present to a certain extent in each individual. In this study, we therefore aimed to extend the current literature by adopting a person-centered approach. More specifically, we aimed to identify groups of adolescents with similar patterns of scores on parent- and peer-related loneliness and negative and positive attitudes toward aloneness. In addition, we aimed to examine whether these groups differed on adolescents' self-esteem and personality, on parental responsiveness and psychological control, and on peer group functioning and friendships. To this aim, we used a multi-informant approach, and included self-report questionnaires, parent-report questionnaires, and peer nominations. Cluster analysis is a technique that uses relations among different constructs to group units into clusters such that units in the same cluster are more alike than units that belong to different clusters (Gore, 2000). Given that cluster solutions may be highly sample-specific, we replicated the clusters in three independent samples, covering a total sample of about 1,800 adolescents. 
Two previous studies conducted a cluster analysis on either of the two relation-specific types of loneliness or the two attitudes toward aloneness. The study focusing on loneliness found four meaningful clusters in two samples of adolescents (Vanhalst, Luyckx, \& Goossens, 2010). These four clusters included a group of adolescents scoring high on both parent- and peer-related loneliness (14\% of mid adolescents and $8 \%$ of late adolescents), low on both ( $44 \%$ of mid adolescents and $41 \%$ of late adolescents), high on parent-related loneliness ( $21 \%$ for both mid and late adolescents), and high on peer-related loneliness (21\% of mid adolescents and $30 \%$ of late adolescents). The study focusing on attitudes toward aloneness found three meaningful clusters in two samples of adolescents. These three clusters included a group of adolescents scoring high on positive attitudes toward aloneness, high on negative attitudes toward aloneness, and low on both attitudes (Teppers et al., 2014). In both the mid and late adolescence sample, each cluster comprised about one third of the participants. Given that no previous research has used both loneliness and attitudes toward aloneness scores in such a person-centered analysis, the present study explored whether groups of adolescents can be identified that share similar patterns of scores regarding loneliness and attitudes toward aloneness.

When such groups of adolescents could be identified, we examined whether some of these groups had specific needs. More specifically, we examined which groups were most vulnerable regarding adolescents' self-esteem and personality, parental responsiveness and psychological control, and peer group functioning and friendships. The findings would then provide suggestions for specific interventions for these groups (e.g., strengthening personal resources, providing assistance regarding relationships with parents, or helping adolescents to build more satisfying relationships with peers). Based on previous, variable centered research, we expected less beneficial correlates for adolescents with high parent- or peer-related loneliness, or high scores on positive attitudes toward aloneness. We therefore expected that 
adolescents in clusters showing high scores on these variables would show less adaptive correlates. Specifically, we expected that a potential cluster of adolescents scoring high on parent-related loneliness would show the most maladaptive scores for parental responsiveness and psychological control, and that a potential cluster of adolescents scoring high on peerrelated loneliness, would show the most maladaptive scores for peer group functioning and friendships.

\section{Method}

\section{Participants}

We conducted the analyses on three independent samples that each included the same loneliness measure but had a unique set of correlates. Data for Sample 1 were collected in 2012 in three secondary schools to investigate loneliness in relation to surface (i.e., selfesteem) and core (i.e., Big Five) personality characteristics. This sample consisted of 266 adolescents $(65.8 \%$ female) from Grade 11 and 12 , aged 16 to 20 years $(M=16.56, S D=$ 0.72). Data on family composition was not available. Data for Sample 2 were collected in 2010 in three secondary schools to examine loneliness in relation to parenting behaviors. This sample consisted of 660 adolescents (49.2\% females) from Grade 9 to 12, aged 13 to 20 years $(M=15.78, S D=1.30)$. Family composition was diverse, including intact families $(81 \%)$, divorced parents $(16 \%)$, and families in which at least one parent had deceased (2\%). In this sample, parents filled out questionnaires on their parenting behavior. Parental participation was $57.2 \%$ for mothers and $49.0 \%$ for fathers. Mothers were 35 to 60 years old $(M=45.59, S D=3.38)$ and fathers were 38 to 66 years old $(M=47.39, S D=3.90)$. Data for Sample 3 were collected in 2009 in three secondary schools, as part of a larger study examining the developmental trend of loneliness across adolescence, its antecedents, and consequences (including peer group functioning). This sample consisted of 904 adolescents (67.7\% females) from Grade 9 to 12 , aged 13 to 21 years $(M=15.79, S D=1.33)$. Family 
composition was diverse, including intact families (71\%), divorced parents (26\%), and families in which at least one parent had deceased (3\%). All of these nine secondary schools are located in the Dutch-speaking part of Belgium and are known to attract mainly Caucasian students from middle class backgrounds.

Questionnaires were administered in the classroom and anonymity was guaranteed. On the day of testing, adolescents could revoke consent at any time. Parents were informed about the study and could revoke consent for the participation of their child (less than $1 \%$ in each sample). The Institutional Review Board approved all study procedures.

\section{Measures}

Loneliness. To measure loneliness and attitudes toward being alone, the Loneliness and Aloneness Scale for Children and Adolescents (LACA; Marcoen et al., 1987) was administered in all three samples. This 48-item scale comprised four subscales of 12 items each, measuring parent- and peer-related loneliness and negative and positive attitudes toward aloneness. Participants answered each item on a 4-point Likert-type scale ranging from (1) often to (4) never. The LACA was originally developed in Belgium, but has been adapted and translated in numerous languages, including Arabic, Chinese, English, French, Greek, Hebrew, Italian, Spanish, and Portuguese. The four-factor structure of the LACA showed superior fit to alternative models and measurement invariance across gender and age (Maes, Klimstra et al., 2015). Previous research further found good reliability (i.e., Cronbach's alpha $>$.80) for the four subscales across a broad range of samples (Maes, Van den Noortgate et al., 2015) and high stability over a 3-month period (median $r=.78$; Goossens, 2015). In the present study, reliability scores were also good in all three samples for parent-related loneliness (e.g., "I feel left out by my parents”; Cronbach’s $\alpha=.90-.92)$, peer-related loneliness (e.g., "I feel sad because I have no friends"; $\alpha=.87-.89$ ), negative attitudes toward 
aloneness (e.g., "When I am alone, I feel bad"; $\alpha=.81-.83$ ), and positive attitudes toward aloneness (e.g., "I want to be alone" ; $\alpha=.82-.86$ ).

Self-esteem. Adolescents' self-esteem was measured in Sample 1 with the SelfPerception Profile for Adolescents (Harter, 1988), using a Likert-type answer format that is less time-consuming, showed similar discriminant validity, and better reliability and convergent validity than the original format (Wichstrøm, 1995). We included the Global SelfWorth subscale (e.g., "I am pretty pleased with myself"; $\alpha=.84$ ) as well as seven specific domains, that is, Scholastic Competence (e.g., "I am pretty slow in finishing my school work" $; \alpha=.67$ ), Social Competence (e.g., "I find it hard to make friends"; $\alpha=.77$ ), Athletic Competence (e.g., "I do very well at all kinds of sports"; $\alpha=91$ ), Physical Appearance (e.g., "I am not happy with the way I look"; $\alpha=.86$ ), Romantic Appeal (e.g., "I feel that if I am romantically interested in someone, that person will like me back"; $\alpha=.65$ ), Behavioral Conduct (e.g., "I do things I know I shouldn't do"; $\alpha=.59$ ), and Close Friendship (e.g., "I am able to make really close friends"; $\alpha=.56$ ). Each subscale consisted of 5 items, which were answered on a 4-point scale ranging from (1) describes me very poorly to (4) describes me very well. The subscale Close Friendship consisted of 4 items. We excluded the item "I can share secrets with my friends", because of its low item-rest correlation.

Big Five personality characteristics. In Sample 1, the Quick Big Five (Goldberg, 1992) assessed the five personality domains using 30 items. The Dutch version (Vermulst \& Gerris, 2005) was reliable in previous research and showed good convergent and divergent validity. On a 7-point Likert-type scale ranging from (1) completely untrue to (7) completely true, participants indicated whether they felt they had certain characteristics such as "talkative" (Extraversion; $\alpha=.85)$, "sympathetic" (Agreeableness; $\alpha=.80)$, "systematic" (Conscientiousness; $\alpha=.91$ ), "worried" (Neuroticism; $\alpha=.87$ ), and "creative" (Openness; $\alpha=$ 84). 
Parental responsiveness. Parental responsiveness was measured in Sample 2 from adolescent, mother, and father perspectives, using 7 items from the Child Report of Parent Behavior Inventory (CRPBI; Schaefer, 1965). The Dutch version was found to be reliable and valid in previous research (Delhaye, Beyers, Klimstra, Linkowskki, \& Goossens, 2012). Regarding the adolescents' perspective (e.g., "My mother / father makes me feel better after talking about my worries with her / him”), Cronbach's $\alpha$ 's were .91 (mothers' responsiveness) and .92 (fathers' responsiveness). Regarding the parents' perspective, the items were revised slightly so that parents could report on their own parenting behavior toward their child (e.g., "I make my son / daughter feel better after talking about his / her worries with me"). Cronbach's $\alpha$ 's were .80 (mothers' responsiveness) and .85 (fathers' responsiveness). All items were answered on a 5-point Likert-type scale ranging from (1) completely untrue to (5) completely true.

Parental psychological control. Parental psychological control was assessed in Sample 2 from adolescent, mother, and father perspectives, using the 8-item Psychological Control Scale - Youth Self-Report (PRS - YSR; Barber, 1996). The validity of this scale has been established in previous research (Barber, Xia, Olsen, McNeely, \& Bose, 2012). Regarding the adolescents' perspective (e.g., "My mother / father is always trying to change how I feel or think about things"), Cronbach's $\alpha$ 's were .83 (mothers' psychological control) and .77 (fathers' psychological control). Regarding the parents' perspective, the items were revised slightly so that parents could report on their own parenting behavior (e.g., "I try to change how my son / daughter feels or thinks about things"). Cronbach's $\alpha$ 's were .75 (mothers' psychological control) and .85 (fathers' psychological control). All items could be answered on a 5-point Likert-type scale ranging from (1) completely untrue to (5) completely true. 
Peer nominations. In Sample 3, participants received an alphabetical list of names of their classmates preceded by a number. For each of the six nomination items, they were asked to consider whom of their classmates fit the description and to write down their corresponding number from the alphabetical list, starting with the number of the peer who fit the description best. An unlimited number of nominations could be given. For each of the items described below, we summed received nominations for each individual and standardized within class. A recent meta-analysis on several dimensions of sociometric status, that is, acceptance, rejection, social preference, and peer ratings, showed good test-retest reliability of these measures (Jiang \& Cillessen, 2005).

Likability and dislikability. Two peer nomination items were used to capture social acceptance. To probe for liability, participants were asked: "Which people in your class do you like the most?". To probe for dislikability, participants were asked: "Which people in you class do you like the least?"

Shyness. Peer nominations were also used to calculate a shyness score. Participants were asked: "Which people in your class are shy and/or socially withdrawn?”.

Aggression. To probe for aggression, participants were asked to nominate classmates that fit the following description: "Which people in your class are aggressive?".

Victimization and bullying. Two peer nominations were used to capture peer victimization and bullying. To probe for victimization, participants were asked: "Which people in you class are victimized?". To probe for bullying, participants were asked: "Which people in your class are bullying others?". A clear definition of victimization was added (see Vanhalst et al., 2014): "By victimization, we mean that someone is mean to someone else, or when that person is threatened, locked up, or kicked. It is called victimization if it happens regularly and if it is difficult for the victim to defend him/herself. It is also called 
victimization if someone is teased often in a mean way. It is not victimization if two people are about equally strong and they argue, fight, or tease one another" (Olweus, 1989).

Friendship quantity. Friendship quantity was assessed in Sample 3 using the peer nomination item "Which people in you class are your best friends?". For each participant, the first five nominations were used to calculate the number of reciprocal friendships (i.e., when the participants nominated a classmate who also nominated that specific participant as a best friend).

Friendship quality. Negative and positive friendship quality were measured in Sample 3. First, participants were asked to concentrate on their best friend. Next, they were asked to keep this best friend in mind while filling out the Friendship Qualities Scale, which has shown good validity (FQS; Bukowski, Hoza, \& Boivin, 1994; Furman, 1996). Negative friendship quality was measured with the 4-item subscale Conflict (e.g., "My friend and I can argue a lot"; $\alpha=.72$ ). Positive friendship quality was measured with 19 items (e.g., "I feel happy when I am with my friend"; $\alpha=.91)$ by merging the subscales Companionship, Help, Security, and Closeness. Participants answered each item on a 5-point Likert-type scale ranging from (1) does not apply to me at all to (5) applies to me very well.

\section{Statistical Analyses}

Before conducting the main analyses, we examined the correlations among the study variables for the three samples separately. We used Cohen's (1988) benchmarks and regarded correlations of .20 as small, correlations of .30 as moderate, and correlations of .50 as large. Next, using cluster analysis for each sample separately, we aimed to group participants into clusters such that participants within a cluster are more alike than participants from different clusters. Before conducting the cluster analyses, we removed the data of participants with missings on the LACA subscales, univariate outliers (i.e., values more than 3 SD below or above the mean), and multivariate outliers (i.e., Mahalanobis distance values greater than 
18.46; Tabachnick, Fidell, \& Osterlind, 2001). In each sample, we conducted the cluster analysis on the remaining adolescents using a two-step procedure (Gore, 2000). First, hierarchical cluster analysis was carried out using Ward's method on squared Euclidian distances. Based on parsimony, interpretability, and explanatory power (i.e., the cluster solution had to explain at least $45 \%$ of the variance in each of the constituting dimensions), the number of clusters was determined. A disadvantage of Ward's method is that when participants are grouped into a cluster, they will remain in that cluster in all subsequent steps, which may result in nonoptimal solutions. Therefore, an additional iterative procedure was included in the second step to optimize the cluster solution and to minimize within-cluster differences. The $k$-means method was used, using Ward's initial cluster centers as nonrandom starting points.

The stability of the final cluster solutions was examined by cross-validating within and between samples. First, each sample was randomly spit into halves. The two-step procedure (i.e., Ward followed by $k$-means) was applied to each half. The final cluster centers obtained for one half of the sample were then used to classify the participants of the other half. Cohen's kappa (к) was used to examine the overlap of these new clusters with the original clusters (Breckenridge, 2000). The two resulting kappas (one for the first half of the sample, the other for the other half) were averaged. An agreement of at least .60 is considered acceptable (Asendorpf, Borkenau, Ostendorf, \& Van Aken, 2001). Second, we cross-validated the clusters between samples by using the final centers of one sample to classify the participants of another sample, and by comparing this new classification with the original classification. The two resulting kappas were again averaged.

Grade and gender differences across the resulting clusters were tested, but were expected to be small. To examine which groups of adolescents were most vulnerable, we conducted a multivariate analysis of variance (MANOVA) on each sample. For Sample 1, 
adolescents' self-esteem and personality were examined. For Sample 2 and 3, we examined parenting and adolescents' peer group functioning and friendships, respectively. Subsequent univariate ANOVAs and post-hoc comparisons, based on Tukey HSD tests to control for Type I error, were used to examine which groups of adolescents differed on which outcome variables. For each ANOVA we report an effect size, that is, partial eta-squared. We used Cohen's (1988) benchmarks and regarded an effect size of .01 as small, of .06 as moderate, and of .14 as large.

\section{Results}

\section{Preliminary Correlational Analyses}

The correlations among the different variables in the respective samples can be found in Tables 1 to 3. The correlations among the subscales of the LACA can be found in all three tables, because this measure was used in each of the samples. Across the samples, small correlations were found between parent- and peer-related loneliness ( $r$ ranging from .10 to .20), which supports the distinction between these two relation-specific types of loneliness. Small correlations were also found between negative and positive attitudes toward aloneness ( $r$ ranging from -.14 to .03), suggesting that these variables are not two opposite ends of the same continuum. The correlation between peer-related loneliness and positive attitudes toward aloneness was consistently moderate ( $r$ ranging from .40 to .44). The other correlations among the LACA subscales were all small (i.e., $r$ s $<.20$ ).

Associations of the LACA subscales with adolescents' self-esteem and personality are presented in Table 1. The LACA subscales, except for the negative attitude to aloneness, were moderately and negatively related with self-esteem. Further, Agreeableness and Emotional stability were weakly to moderately and negatively related with all four LACA subscales. Conscientiousness was moderately related with parent-related loneliness only. Extraversion was not related with negative attitudes toward aloneness, but was moderately to strongly and 
negatively related with the three other subscales. Openness to experience was not related with loneliness, and weakly related with negative and positive attitudes toward aloneness

Associations between the LACA subscales and parental responsiveness and psychological control are presented in Table 2. Parent-related loneliness was negatively related with parents' responsiveness and positively with parents' psychological control. These correlations were large when reported by the adolescents. A similar pattern was observed for the three other subscales, although correlations were small (adolescents' perspective) or nonsignificant (parents' perspective).

Associations between the LACA subscales and adolescents' peer group functioning and friendships are presented in Table 3. Peer-, but not parent-related loneliness and negative, but not positive attitude toward aloneness, were weakly to moderately related with both likability and dislikability. Peer-related loneliness was further moderately and positively related with shyness and victimization and weakly and negatively with bullying. Parentrelated loneliness was weakly and positively related with aggression and bullying. Friendship quantity and quality were negatively related with peer-related loneliness and positive attitudes, and positively with negative attitudes toward aloneness. Conflict was positively related with peer-related loneliness and negative attitudes toward aloneness. These relations with peer-related loneliness were moderate in size, whereas the others were generally weak in size.

\section{Cluster Analysis of Loneliness and Attitudes Toward Being Alone}

To find groups of adolescents with similar scores on parent- and peer-related loneliness and negative and positive attitudes toward aloneness, we conducted a cluster analysis. For the three samples, we removed participants with missing data (i.e., 12, 31, and 12 participants, respectively), univariate outliers (i.e., 7, 15, and 21 participants, respectively) and multivariate outliers (i.e., 0, 1, and 4 participants, respectively). Cluster analyses on the 
remaining adolescents revealed a six-cluster solution in all three samples (Figure 1, Panels A to C), explaining 51-62\% of the variance in parent-related loneliness, $54-59 \%$ in peer-related loneliness, $53-61 \%$ in negative attitudes, and 51-57\% in positive attitudes toward aloneness. Cross-validation within samples resulted in adequate kappas of .71 (Sample 1), .71 (Sample 2), and .67 (Sample 3). Cross-validation between samples resulted in equally adequate kappas of .67 (Sample 1), .67 (Sample 2), and .74 (Sample 3).

The Indifference cluster (17-23\% of the sample) consisted of adolescents scoring moderately low on parent-related loneliness and low on peer-related loneliness and attitudes toward aloneness. The Moderate cluster (18-25\%), was characterized by moderately low parent-related loneliness, average peer-related loneliness, and moderately high attitudes toward aloneness. A variation on this pattern emerged in Sample 3, where adolescents scored moderately low on negative attitudes toward aloneness. The Negative Attitude cluster (16$21 \%$ ) consisted of adolescents with high scores on negative attitudes toward aloneness and low scores on positive attitudes. For parent- and peer-related loneliness, moderately low scores were found. A variation on this pattern emerged in Sample 3, where adolescents had average scores on positive attitudes toward aloneness. The Parent-Related Loneliness cluster (9-16\%) was characterized by high parent-, but not peer-related loneliness. Adolescents in this cluster were further characterized by high negative attitudes and average positive attitudes toward aloneness. A variation on this pattern emerged in Sample 2, where adolescents showed average negative attitudes toward aloneness. The Peer-Related Loneliness cluster (12-19\%) was characterized by high peer-, but not parent-related loneliness. Adolescents in this cluster were further characterized by average negative attitudes and high positive attitudes toward aloneness. A variation on this pattern emerged in Sample 3, where adolescents showed moderately high negative and positive attitudes toward aloneness. The Positive Attitude cluster (10-14\%) consisted of adolescents scoring high on positive attitudes and low on 
negative attitudes toward aloneness. Adolescents in this cluster further showed moderately high parent- and peer-related loneliness. A variation on this pattern emerged in Sample 2 where the adolescents showed average parent- and peer-related loneliness. The variations on the cluster patterns presumably reflected specific characteristics of the samples. Aggregating the results of the three samples is a useful method for carving out consistencies (Asendorpf et al., 2001). Panel D (Figure 1) shows the mean pattern across the three samples for the obtained clusters.

We further tested whether the clusters differed in gender and grade distribution. Some gender and grade differences were found, but, as expected, effect sizes were small. For Sample 1, we found differences in gender distribution $\left(\chi^{2}(5)=13.00, p=.02, \varphi=.22\right)$, but not in grade distribution $\left(\chi^{2}(5)=8.75, p=.12, \varphi=.18\right)$. More boys were found in the Indifference cluster. For Sample 2, we also found gender $\left(\chi^{2}(5)=15.19, p=.01, \varphi=.15\right)$ and grade $\left(\chi^{2}(15)\right.$ $=43.82, p<.001, \varphi=.25)$ differences. More boys were found in the Indifference cluster and fewer boys in the Moderate cluster. Further, fewer adolescents from Grade 9 and more adolescents from Grade 12 were found in the Positive Attitude cluster. For Sample 3, we found differences in both gender $\left(\chi^{2}(5)=29.10, p<.001, \varphi=.18\right)$ and grade $\left(\chi^{2}(15)=29.18\right.$, $p=.02, \varphi=.18$ ) distributions. More boys were found in the Indifference cluster and fewer boys in the Negative Attitude cluster. Further, more adolescents from Grade 9 were found in the Indifference cluster and fewer adolescents from Grade 9 in the Peer-Related Loneliness cluster.

\section{Correlates of the Loneliness and Attitudes Toward Aloneness Profiles}

Adolescents' self-esteem and personality. A multivariate analysis of variance showed significant cluster differences on adolescents' self-esteem and personality in Sample 1 $\left(F_{\text {Pillai }}(65,1135)=3.48, p<.001, \eta^{2}=.17\right)$. Subsequent univariate ANOVAs revealed 
significant cluster differences for all variables, except for the self-esteem domain Behavioral Conduct and the personality domain Openness to experience (Table 4).

Self-esteem. Post-hoc comparisons based on Tukey HSD Tests revealed significant cluster differences on adolescents' self-esteem. Adolescents in the Peer-Related Loneliness and in the Positive Attitude clusters had lower global self-esteem than the other adolescents, with the exception of adolescents in the Parent-Related Loneliness group. Adolescents in the Indifference cluster had the highest global self-esteem, though they were not significantly different from the Moderate and Negative Attitude clusters. Adolescents in the Peer-related Loneliness and Positive Attitude clusters also rated themselves lower on social competence, athletic competence, and close friendship competence compared to the other four clusters. Regarding scholastic competence, results revealed the lowest scores for adolescents in the Positive Attitude cluster, though these adolescents were not significantly different from adolescents in the Parent- and Peer-Loneliness groups. Regarding physical appearance, adolescents in the Indifference cluster scored highest, whereas adolescents in the Positive Attitude and Peer- and Parent-Related Loneliness clusters scored lower. Finally, adolescents in the Peer-Related Loneliness cluster scored lower on romantic appeal than the other adolescents, though not significantly different from the Positive Attitude cluster. Overall, adolescents in the Peer-Related Loneliness and Positive Attitude clusters had the least positive self-esteem. Compared to adolescents in the Parent-Related Loneliness cluster, adolescents in Peer-Related Loneliness cluster scored lower on social competence, athletic competence, romantic appeal, and close friendship. Effect sizes for scholastic and athletic competence were small to moderate, for physical appearance and romantic appeal moderate to large, and for global self-esteem, social competence, and close friendship large.

Personality. Significant cluster differences were found on the five personality domains. Adolescents in the Positive Attitude cluster were less agreeable than adolescents in 
the Moderate cluster. Regarding conscientiousness, adolescents in both the Positive Attitude cluster and the Parent-Related Loneliness cluster scored lowest. Adolescents in the PeerRelated Loneliness cluster also were less extraverted and emotionally stable, though not significantly different from adolescents in the Positive Attitude cluster. By contrast, adolescents in the Negative Attitude and Indifference cluster scored highest on these two personality domains. Adolescents in the Peer-Related Loneliness and the Positive Attitude clusters showed the lowest levels of extraversion. Effect sizes were moderate, with a large effect for extraversion.

Parental responsiveness and psychological control. A multivariate analysis of variance showed significant cluster differences on parental responsiveness and psychological control in Sample $2\left(F_{\text {Pillai }}(40,1420)=3.79, p<.001, \eta^{2}=.10\right)$. Subsequent univariate ANOVAs revealed significant cluster differences for all variables, except for mothers' responsiveness and fathers' psychological control from their own perspective (Table 5).

Adolescent perspective. Post-hoc comparisons based on Tukey HSD Tests revealed significant cluster differences on parenting behaviors from the adolescents' perspective. Adolescents in the Parent-Related Loneliness cluster reported the least responsiveness of both father and mother, followed by adolescents in the Peer-Related Loneliness cluster. Adolescents in the Parent-Related Loneliness cluster reported the highest parental psychological control. Effect sizes for responsiveness were large and for psychological control moderate.

Mother perspective. Although univariate tests revealed cluster differences in psychological control from the mothers' perspective, post-hoc tests revealed no differences.

Father perspective. Univariate tests revealed cluster differences in responsiveness from the fathers' perspective. Fathers with adolescents in the Parent-Related Loneliness cluster tended to report the least responsiveness, but the effect size was small. 
Adolescents' peer group functioning and friendships. A multivariate analysis of variance showed significant cluster differences on peer group functioning and friendships in Sample $3\left(F_{\text {Pillai }}(45,3840)=3.74, p<.001, \eta^{2}=.04\right)$. Subsequent univariate ANOVAs revealed significant cluster differences for all variables, except for the peer nomination Aggression (Table 6).

Peer nominations. Significant cluster differences were found on the peer nomination variables. Adolescents in the Peer-Related Loneliness and Positive Attitude clusters were less liked and more disliked by their peers. According to their peers, adolescents in the PeerRelated Loneliness cluster were further seen as more shy and more likely to be identified as victims of bullying than adolescents in the other clusters. Adolescents in the Peer-Related Loneliness cluster were less often seen as bullies, whereas adolescents in the Parent-Related Loneliness cluster were more often seen as bullies. Adolescents in the Positive Attitudes cluster were not significantly different from adolescents in the Peer-Related Loneliness cluster, but scores were less extreme. Effect sizes were small to moderate (e.g., likability and victimization).

Friendships. Significant cluster differences were found for friendship quantity and quality, and conflict. Adolescents in the Peer-Related Loneliness and Positive Attitude clusters scored lower on friendship quantity and quality than the other adolescents. Adolescents in the Positive Attitude cluster reported the most conflict, though not significantly worse than adolescents in the two Loneliness clusters. Adolescents in the Indifference cluster had the least conflict, though not significantly different from adolescents in the Moderate and Negative Attitude clusters. Effect sizes were moderate.

\section{Discussion}

During adolescence, loneliness tends to increase (Qualter et al., 2015) and as adolescents spend an increasing amount of time on their own, they learn to use this time alone 
in a more deliberate way, for example, for emotional self-regulation and identity development (Larson, 1997; Long \& Averill, 2003). Earlier research has distinguished between adolescent loneliness as experienced in different relationships (i.e., with parents and peers) and between positive and negative attitudes to being alone (Marcoen \& Goossens, 1993). So far, the correlates of each of these constructs (e.g., associations with personality traits; Teppers et al., 2013) have been examined using a variable-centered approach, thereby neglecting the coocurrence between loneliness and attitude to aloneness. The present study examined patterns of co-occurrence between relation-specific types of loneliness and attitudes toward aloneness by adopting a person-centered approach, that is, cluster analysis. In three independent samples, covering a total sample of about 1,800 adolescents, we found six groups of adolescents each with a unique profile of scores on parent- and peer-related loneliness and positive and negative attitudes toward being alone. In addition, we examined whether some of these groups would be more vulnerable regarding adolescents' self-esteem and personality, parental responsiveness and psychological control, and peer group functioning and friendships. To this aim, we adopted a multi-informant approach, including self-report questionnaires, parent-report questionnaires, and peer nominations. We found that the six groups of adolescents could be differentiated in a meaningful way. Three of these groups (i.e., Indifference, Moderate, and Negative Attitude), showed an adaptive profile, whereas the three other groups (i.e., Parent-Related Loneliness, Peer-Related Loneliness, and Positive Attitude) showed a more maladaptive profile and may need specific assistance.

\section{Loneliness and Attitudes Toward Aloneness Profiles}

Six groups of adolescents were identified, each of which showed a unique profile of scores on parent- and peer-related loneliness as well as negative and positive attitudes toward aloneness. One group of adolescents, labelled the Indifference group, showed moderately low to low scores on both types of loneliness and on both negative and positive attitudes. A 
second group of adolescents, labelled the Moderate group, showed moderately low loneliness in relation with their parents and average loneliness in relation with their peers. These adolescents further showed moderately high negative and positive attitudes toward aloneness. Adolescents in a third group, that is, the Negative Attitude group, were highly negative toward aloneness and reported moderately low loneliness in relation with both parents and peers. Adolescents in a fourth group, the Parent-Related Loneliness group, reported high feelings of loneliness in relation with their parents, but not with their peers. These adolescents further scored high on negative attitudes, and average on positive attitudes toward aloneness. A fifth group of adolescents, the Peer-Related Loneliness group, reported high feelings of loneliness in relation with their peers, but not with their parents. These adolescents further scored high on positive attitudes, and average on negative attitudes toward aloneness. Adolescents in a sixth group, which was labelled the Positive Attitude group, were highly positive about aloneness, but also reported high feelings of loneliness in both their relation with their parents and peers. These adolescents further showed low negative attitudes toward aloneness. Across the three samples, we found that more boys than expected by change were in the Indifference group. Some other gender and age differences in the distribution among the six clusters were also found, but these were not consistent across samples and represented small effect sizes.

The pattern of loneliness and attitudes toward aloneness scores of these six groups of adolescents corroborates previous research that advocates hybrid multidimensional models to examine loneliness and attitudes toward aloneness (Goossens et al., 2009; Houghton et al., 2014; Maes, Klimstra et al., 2015; Majorano et al., 2015). Regarding the two relation-specific types of loneliness, we found a group of adolescents who were lonely in the relation with their parents only, and another group of adolescents who were lonely in the relation with their peers only. Strikingly, these two groups of adolescents showed different attitudes toward 
aloneness. Adolescents who were lonely in the relation with their parents were negative toward aloneness, whereas adolescent who were lonely in the relation with their peers were positive toward aloneness. Some of the items of the negative attitudes subscale refer to the peer group (e.g., "When I am lonesome, I got to see some friends"). It might be that when adolescents do not feel connected with or understood by their parents, they turn to their peers to get the support that they are looking for. However, when adolescents are lonely in relation with their peers, they will likely not receive support from their peer group. Being positive toward aloneness might for these adolescents be a way of coping with their experiences of loneliness (Vanhalst, Goossens, Luyckx, Scholte, \& Engels, 2013). Feelings of loneliness arise when there is a discrepancy between actual and desired social relationships. Being more positive toward aloneness lowers these expectations, which decreases the discrepancy leading to lower feelings of loneliness. Alternatively, being positive toward aloneness might lead to higher levels of loneliness, because by spending more time on their own, adolescents might miss too many opportunities to interact with peers, leading to experiences of loneliness in the peer context (Wang et al., 2013). Longitudinal research is needed to understand the link between loneliness and attitudes toward aloneness better.

In contrast to prior research (Vanhalst et al., 2010), we did not find a group of adolescents reporting high levels of loneliness in the relations with both their parents and peers. However, adolescents in the Positive Attitude group showed moderately high parentand peer-related loneliness. The co-occurrence of parent- and peer-related loneliness was thus present in the current study, but to a lesser extent than in previous research. Interestingly, adolescents in the Negative Attitude group showed moderately low parent- and peer-related loneliness. This finding confirms earlier research suggesting that an overly positive attitude toward aloneness might be maladaptive (Larson, 1990; Wang et al., 2013). 
The present study also adds to the growing evidence that negative and positive attitudes are not two opposite ends of the same continuum (Maes, Klimstra et al., 2015). In addition to groups of adolescents that had either negative or positive attitudes toward aloneness, we found a group of adolescents with moderately high to high scores on both types of attitudes (i.e., the Peer-Related Loneliness group). Moreover, we found an Indifference group in which the adolescents scored low on both negative and positive attitudes toward aloneness. Adolescents in the Indifference and the Moderate groups showed a different profile in terms of attitudes toward aloneness, but no significant group differences were found regarding the examined correlates. Having either low or average negative and positive attitudes toward aloneness does not seem to be associated with adolescents' adjustment.

\section{Correlates of the Loneliness and Attitudes Toward Aloneness Profiles}

The six groups of adolescents were compared regarding their self-esteem and personality, parental responsiveness and psychological control, and peer group functioning and friendships. Across the three samples we found that three of the groups showed rather adaptive correlates. These adaptive correlates were shown by adolescents in the Indifference, Moderate, and Negative Attitude groups. Adolescents in the three other groups, that is, the Parent-Related Loneliness, Peer-Related Loneliness, and Positive Attitude groups, showed less adaptive correlates.

Regarding adolescents' self-esteem, adolescents in the Parent-Related Loneliness, Peer-Related Loneliness, and Positive Attitude groups, showed the lowest global self-esteem. This is in line with the evolutionary theory of loneliness, which proposes that in lonely people a survival mechanism is activated that heightens sensitivity to threats, which is accompanied by negative feelings such as stress and low self-esteem (Hawkley \& Cacioppo, 2010). When examining subdomains of self-esteem, adolescents in the Peer-Related Loneliness and Positive Attitude groups showed lower self-esteem in the domains of social competence, 
athletic competence, physical appearance, romantic appeal, and close friendship. Strikingly, both of these two groups had moderately high to high scores on peer-related loneliness and positive attitudes toward aloneness. It is not surprising that adolescents in the Parent-Related Loneliness group did show strong effects in these subdomains, as these subdomains are more relevant in the peer context. Also, the Sociometer Hypothesis (Leary et al., 1995) states that self-esteem functions as a sociometer that monitors the extent to which an individual is included or excluded by other people. This too might be more likely in the peer than in the parent context.

Regarding the Big Five personality characteristics, our results were partly in line with prior research (Teppers et al., 2013). That is, adolescents in the Peer-Related Loneliness and Positive Attitude groups were characterized by low extraversion, adolescents in the PeerRelated Loneliness group showed low emotional stability, and adolescents in the ParentRelated Loneliness group were less conscientious. Also in agreement with Teppers et al. (2013), adolescents in the Positive Attitudes group were less agreeable than adolescents in the Moderate group. In contrast to prior research, adolescents with high positive attitudes to being alone were less conscientious and no significant differences were found between the groups in openness. It might be that low agreeableness, emotional instability, low conscientiousness, and introversion, reduce social attractiveness and have a negative effect on one's interactional behavior and one's reactions to changes in social relationships (Peplau \& Perlman, 1982). However, these personality characteristics might not be equally important for different relationships. It could be, for example, that conscientiousness is more valued by parents, whereas extraversion is more valued by peers. More research in this regard is needed to confirm these hypotheses.

The groups of adolescents were also compared regarding parental responsiveness and psychological control from their own perspective and the perspective of their mothers and 
fathers. In line with previous research (Scharf et al., 2011), adolescents in the Parent-Related Loneliness group reported lower parental responsiveness and higher parental psychological control than adolescents in any other group. The same pattern was found when parents themselves reported on their parenting behavior, but the effects were small or non-significant. Attachment theory and empirical work suggested that adolescents develop an internal working model based on their experiences with their parents, which they generalize to their relationships with peers (Cassidy \& Berlin, 1999; Rotenberg, 1999; Scharf et al., 2011). In line with this work, we found that adolescents in the Peer-Related Loneliness group reported lower responsiveness from both father and mother compared to adolescents with low loneliness scores.

We examined different types of peer relations, including the larger peer group and dyadic friendships, as proposed by the social needs perspective (Sullivan, 1953; Weiss, 1973). As expected, adolescents in the Peer-Related Loneliness and Positive Attitude group were less liked and more disliked by their peers than adolescents in the other groups. Adolescents in the Peer-Related Loneliness group were also more often identified by their peers as shy and as being a victim of bullying, and were less often seen as bullies. Adolescents in the PeerRelated Loneliness group further had the least friends and reported the lowest friendship quality. Adolescents in the Positive Attitude group showed a similar pattern regarding their friendships, but with less extreme scores. These adolescents also reported more conflict in their friendships.

To summarize, we found, as expected, that adolescents in the Parent-Related Loneliness group showed less adaptive correlates regarding parenting behaviors, followed by adolescents in the Peer-Related Loneliness group. Adolescents in the Peer-Related Loneliness and Positive Attitudes groups showed the least adaptive correlates regarding peer groups functioning and friendships. One implication of these findings is that, even though time 
spending alone might become more adaptive in adolescence (Larson, 1997; Long \& Averill, 2003), too much time alone might be maladaptive as adolescents might miss important opportunities for social interactions (Wang et al., 2013). Another implication of our study is that adolescents experiencing parent- or peer-related loneliness seem to need specific assistance, that is, regarding either their relations with their parents or with their peers, respectively. However, the large majority of studies on adolescents' loneliness still uses either the UCLA Loneliness Scale (Russell, Peplau, \& Cutrona, 1980) or the Children's Loneliness Scale (CLS; Asher, Hymel, \& Renshaw, 1984). Both of these scales are unidimensional and, based on their item content and factor analyses, tap mostly into peer-related loneliness (Goossens \& Beyers, 2002; Goossens et al., 2009). In the majority of studies on adolescents' loneliness, we are thus likely to overlook those adolescents who experience parent-related loneliness and who might need assistance in this particular context.

\section{Strengths and Limitations}

The present study has a number of important strengths. First, we adopted a personcentered approach, that is, cluster analysis, to examine the co-occurrence between adolescents' loneliness and their attitudes toward aloneness that had previously been neglected. Second, we replicated the different groups of adolescents that resulted from the cluster analysis across three independent samples, covering a total sample of about 1,800 adolescents. Third, we adopted a multi-informant approach and included self-reported questionnaires, parent-reported questionnaires, and peer nominations. Fourth, based on Bronfenbrenner's (1977) ecological model of human development, we examined not only adolescents' personal characteristics, but also included the parent and peer context. The broad set of correlates that was examined, allowed us to differentiate clearly between the clusters. Our study, therefore, expands the extant literature on adolescent loneliness and attitudes to being alone through its careful use of measures and statistical methods. 
However, there are also some limitations to keep in mind when interpreting the results. First, all three samples were collected in the Dutch-speaking part of Belgium in schools that are known to attract mainly Caucasian middle class students, so the findings might not be generalizable beyond this particular population. Second, different outcome variables were administered in each of these samples so that we were unable to compare the groups on the same outcome variables across the three samples. Third, some of the subscale scores of the Self-Perception Profile for Adolescents (Harter, 1988), especially the Close Friendship subscale, had somewhat low reliabilities. Fourth, the present study was cross-sectional, so we cannot examine the direction of effects. The examined correlates may be predictors as well as outcomes of loneliness and attitudes toward aloneness, and some of the relations are likely to be bidirectional. Moreover, it would be interesting to see whether adolescents change from one profile to another over time and how such changes relate to their adjustment. Fifth, although our study examined variables related with both the larger peer group and dyadic friendships, future research might also examine whether different subtypes of peer-related loneliness can be distinguished. In the current study, we used a subscale that mostly taps into peer group loneliness (i.e., feelings of lacking a network of social relationships. Other questionnaires, such as the Peer Network and Dyadic Loneliness Scale (PNDLS; Hoza, Bukowski, \& Beery, 2000), also tap into peer dyadic loneliness (i.e., feelings of lacking a close, intimate attachment to another person). Finally, in line with Bronfenbrenner's (1977) ecology of human development, we examined, in addition to personal characteristics, characteristics from the parent and peer context. However, other systems might be important as well, including the neighborhood these adolescents live in or the larger cultural community. Future replication efforts, therefore, should concentrate on adolescents with different cultural and socio-economic backgrounds, a broader set of correlates, and alternative social contexts, and rely on designs that are developmentally sensitive and provide hints about the direction of 
effects in the chain of events that link loneliness and attitude to being alone to their supposed correlates.

\section{Conclusion}

The present study moved beyond one of the major limitations of current work on adolescent loneliness and attitudes toward aloneness, that is, its neglect of the co-occurrence among the different constructs involved through the use of simple correlational techniques. Using an innovative, person-centered approach, the present study identified six groups of adolescents, each with a unique profile regarding parent- and peer-related loneliness and negative and positive attitudes toward aloneness. Three of these groups showed an adaptive pattern of correlates regarding adolescents' self-esteem and personality, parental responsiveness and psychological control, and peer group functioning and friendships. Less adaptive correlates were found for adolescents in the Parent-Related Loneliness, Peer-Related Loneliness, and Positive Attitudes groups. These results provide initial clues to the specific needs of intervention these groups could benefit from (i.e., assistance with relationships with parents for the first group, and assistance with relationships with peers for the other two groups). Our findings further indicated that the two forms of loneliness, in the parental and peer realm, respectively, can be clearly distinguished and that negative and positive attitudes toward aloneness do not represent two extremes on the same continuum (c.f., Maes, Klimstra et al., 2015). As a result, researchers who wish to investigate loneliness and its associated variables, may want to adopt a multidimensional approach (Goossens et al., 2009) instead of a global or undifferentiated one. The present study, therefore, represents an important step toward a better understanding and improved measurement of adolescent loneliness and attitudes to being alone. 


\section{References}

Asendorpf, J. B., Borkenau, P., Ostendorf, F., \& Van Aken, M. A. G. (2001). Carving personality description at its joints: Confirmation of three replicable personality prototypes for both children and adults. European Journal of Personality, 15, 169198. doi:10.1002/per.408

Asendorpf, J. B., \& Van Aken, M. A. (2003). Personality-relationship transaction in adolescence: Core versus surface personality characteristics. Journal of Personality, 71, 629-666. doi:10.1111/1467-6494.7104005

Asher, S. R., Hymel, S., \& Renshaw, P. D. (1984). Loneliness in children. Child Development, 55, 1456-1464. doi:10.2307/1130015

Barber, B. K. (1996). Parental psychological control: Revisiting a neglected construct. Child Development, 67, 3296-3319. doi:10.1111/1467-8624.ep9706244861

Barber, B. K., Xia, M., Olsen, J. A., Mcneely, C. A., \& Bose, K. (2012). Feeling disrespected by parents: Refining the measurement and understanding of psychological control. Journal of Adolescence, 35, 273-287. doi:10.1016/j.adolescence.2011.10.010

Bowker, J., \& Spencer, S. (2010). Friendship and adjustment: A focus on mixed-grade friendships. Journal of Youth and Adolescence, 39, 1318-1329. doi:10.1007/s10964009-9474-0

Breckenridge, J. N. (2000). Validating cluster analysis: Consistent replication and symmetry. Multivariate Behavioral Research, 35, 261-285.doi:10.1207/S15327906mbr3502_5

Brighi, A., Guarini, A., Melotti, G., Galli, S., \& Genta, M. L. (2012). Predictors of victimisation across direct bullying, indirect bullying and cyberbullying. Emotional and Behavioural Difficulties, 17, 375-388. doi:10.1080/13632752.2012.704684

Bronfenbrenner, U. (1977). Towards an experimental ecology of human development. American Psychologist, 32, 513-531. doi:10.1037//0003-066X.32.7.513 
Bukowski, W. M., Hoza, B., \& Boivin, M. (1994). Measuring friendship quality during preand early adolescence: The development and psychometric properties of the friendship qualities scale. Journal of Social and Personal Relationships, 11, 471-484. doi:10.1177/0265407594113011

Cacioppo, J. T., Cacioppo, S., Cole, S. W., Capitanio, J. P., Goossens, L., \& Boomsma, D. I. (2015). Loneliness across phylogeny and a call for comparative studies and animal models. Perspectives on Psychological Science, 10, 202-212. doi:10.1177/1745691614564876

Caspi, A., Roberts, B. W., \& Shiner, R. L. (2005). Personality development: Stability and change. Annual Review of Psychology, 56, 453-484. doi:10.1146/annurev.psych.55.090902.141913

Cassidy, J., \& Berlin, L. J. (1999). Understanding the origins of childhood loneliness: Contributions of attachment theory. In K. J. Rotenberg \& S. Hymel (Eds.), Loneliness in childhood and adolescence (pp. 34-55). New York, NY: Cambridge University Press.

Cheng, H., \& Furnham, A. (2002). Personality, peer relations, and self-confidence as predictors of happiness and loneliness. Journal of Adolescence, 25, 327-339. doi:10.1006/jado.2002.0475

Cohen, J. (1988). Statistical power analysis for the behavioral sciences (2nd ed.). Hillsdale, NJ: Erlbaum.

Corsano, P., Majorano, M., \& Champretavy, L. (2006). Psychological well-being in adolescence: The contribution of interpersonal relations and experience of being alone. Adolescence, 41, 341-353. 
Delhaye, M., Beyers, W., Klimstra, T. A., Linkowski, P., \& Goossens, L. (2012). The Leuven Adolescent Perceived Parenting Scale (LAPPS). Psychologica Belgica, 52, 289-305. doi:10.5334/pb-52-4-289

Furman, W. (1996). The measurement of friendship perceptions: Conceptual and methodological issues. In W. M. Bukowski, A. F. Newcomb, \& W. W. Hartup (Eds.), The company they keep: Friendship in childhood and adolescence (pp. 41-65). New York, NY: Cambridge University Press.

Goldberg, L. R. (1992). The development of markers for the Big-Five factor structure. Psychological Assessment, 4, 26-42. doi:10.1037/1040-3590.4.1.26

Goossens, L. (2006). Affect, emotion, and loneliness in adolescence. In S. Jackson \& L. Goossens (Eds.), Handbook of adolescent development (pp. 51-70). Hove, UK: Psychology Press.

Goossens, L. (Ed.). (2015). De Leuvense Eenzaamheidsschaal voor Kinderen en Adolescenten: Handleiding [Loneliness and Aloneness Scale for Children and Adolescents: Manual]. Unpublished manuscript, Leuven, Belgium.

Goossens, L., \& Beyers, W. (2002). Comparing measures of childhood loneliness: Internal consistency and confirmatory factor analysis. Journal of Clinical Child and Adolescent Psychology, 31, 252-262. doi:10.1207/153744202753604520

Goossens, L., Lasgaard, M., Luyckx, K., Vanhalst, J., Mathias, S., \& Masy, E. (2009). Loneliness and solitude in adolescence: A confirmatory factor analysis of alternative models. Personality and Individual Differences, 47, 890-894. doi:10.1016/j.paid.2009.07.011

Gore, P. A. (2000). Cluster analysis. In H. E. A. Tinsley \& S. D. Brown (Eds.), Handbook of applied multivariate statistics and mathematical modeling. San Diego, CA: Academic Press. 
Grøholt, B., Ekeberg, Ø., Wichstrøm, L., \& Haldorsen, T. (2005). Suicidal and nonsuicidal adolescents: Different factors contribute to self-esteem. Suicide and Life-Threatening Behavior, 35, 525-535. doi:10.1521/suli.2005.35.5.525

Harter, S. (1988). Manual for the Self-Perception Profile for Adolescents. Denver, CO: University of Denver.

Hawkley, L. C., \& Capitanio, J. P. (2015). Perceived social isolation, evolutionary fitness and health outcomes: A lifespan approach. Philosophical Transactions of the Royal Society B, 370, 20140114. doi:10.1098/rstb.2014.0114.

Hawkley, L. C., \& Cacioppo, J. T. (2010). Loneliness matters: A theoretical and empirical review of consequences and mechanisms. Annals of Behavioral Medicine, 40, 218227. doi:10.1007/s12160-010-9210-8

Houghton, S., Hattie, J., Wood, L., Carroll, A., Martin, K., \& Tan, C. (2014). Conceptualising loneliness in adolescents: Development and validation of a self-report instrument. Child Psychiatry \& Human Development, 45, 604-616. doi:10.1007/s10578-0130429-z

Jiang, X. L., \& Cillessen, A. H. N. (2005). Stability of continuous measures of sociometric status: A meta-analysis. Developmental Review, 25, 1-25. doi:10.1016/j.dr.2004.08.008

Kochanska, G., \& Kim, S. (2013). Early attachment organization with both parents and future behavior problems: From infancy to middle childhood. Child development, 84, 283296. doi:10.1111/j.1467-8624.2012.01852.x

Ladd, G. W., Kochenderfer, B. J., \& Coleman, C. C. (1997). Classroom peer acceptance, friendship, and victimization: Distinct relational systems that contribute uniquely to children's school adjustment? Child Development, 68, 1181-1197. doi:10.1111/j.14678624.1997.tb01993.x 
Larson, R. W. (1990). The solitary side of life: An examination of the time people spend alone from childhood to old age. Developmental Review, 10, 155-183. doi:10.1016/0273-2297(90)90008-R

Larson, R. W. (1997). The emergence of solitude as a constructive domain of experience in early adolescence. Child Development, 68, 80-93. doi: 10.1111/j.14678624.1997.tb01927.x

Larson, R. W., Richards, M. H., Moneta, G., Holmbeck, G., \& Duckett, E. (1996). Changes in adolescents' daily interactions with their families from ages 10 to 18: Disengagement and transformation. Developmental Psychology, 32, 744-754. doi:10.1037/00121649.32.4.744

Leary, M. R., Tambor, E. S., Terdal, S. K., \& Downs, D. L. (1995). Self-esteem as an interpersonal monitor: The sociometer hypothesis. Journal of Personality and Social Psychology, 68, 518-530.

Long, C. R., \& Averill, J. R. (2003). Solitude: An exploration of benefits of being alone. Journal for the Theory of Social Behaviour, 33, 21-44. doi:10.1111/1468-5914.00204

Maes, M., Klimstra, T., Van den Noortgate, W., \& Goossens, L. (2015). Factor structure and measurement invariance of a multidimensional loneliness scale: Comparisons across gender and age. Journal of Child and Family Studies, 24, 1829-1837. doi:10.1007/s10826-014-9986-4

Maes, M., Van Den Noortgate, W., \& Goossens, L. (2015). A reliability generalization study for a multidimensional loneliness scale: The Loneliness and Aloneness Scale for Children and Adolescents. European Journal of Psychological Assessment. Advance online publication. doi:10.1027/1015-5759/a000237 
Mahon, N. E., Yarcheski, A., Yarcheski, T. J., Cannella, B. L., \& Hanks, M. M. (2006). A meta-analytic study of predictors for loneliness during adolescence. Nursing Research, $55,308-315$.

Marcoen, A., \& Goossens, L. (1993). Loneliness, attitude towards aloneness, and solitude: Age differences and developmental significance during adolescence. In S. Jackson \& H. Rodriguez-Tome (Eds.), Adolescence and its social worlds (pp. 197-227). Hove, UK: Erlbaum.

Marcoen, A., Goossens, L., \& Caes, P. (1987). Loneliness in pre through late adolescence: Exploring the contributions of a multidimensional approach. Journal of Youth and Adolescence, 16, 561-577. doi:10.1007/bf02138821

Majorano, M., Musetti, A., Brondino, M., \& Corsano, P. (2015). Loneliness, emotional autonomy and motivation for solitary behavior during adolescence. Journal of Child and Family Studies. Advance online publication. doi:10.1007/s10826-015-0145-3

Meeus, W., \& Deković, M. (1995). Identity development, parental and peer support in adolescence: Results of a national Dutch survey. Adolescence, 30, 931-944.

Olweus, D. (1989). The Olweus bully/victim questionnaire. Bergen, Norway: Mimeo.

Pallini, S., Baiocco, R., Schneider, B. H., Madigan, S., \& Atkinson, L. (2014). Early childparent attachment and peer relations: A meta-analysis of recent research. Journal of Family Psychology, 28, 118-123. doi:10.1037/a0035736

Peplau, L. A., \& Perlman, D. (1982). Perspectives on loneliness. In L. A. Peplau \& D. Perlman (Eds.), Loneliness: A sourcebook of current theory, research and therapy (pp. 1-18). New York, NY: Wiley.

Perlman, D., \& Peplau, L. A. (1981). Towards a social psychology of loneliness. In S. Duck \& R. Gilmour (Eds.), Personal relationships in disorder (Vol. 3, pp. 31-56). London, UK: Academic Press. 
Qualter, P., Vanhalst, J., Harris, R. A., Van Roekel, E., Lodder, G., Bangee, M., . . Verhagen, M. (2015). Loneliness across the life span. Perspectives on Psychological Science, 10, 250-264. doi:10.1177/1745691615568999

Rotenberg, K. J. (1999). Parental antecedents of children's loneliness. In K. J. Rotenberg \& S. Hymel (Eds.), Loneliness in childhood and adolescence (pp. 176-200). New York, NY: Cambridge University Press.

Russell, D. W., Cutrona, C. E., Mcrae, C., \& Gomez, M. (2012). Is loneliness the same as being alone? Journal of Psychology, 146, 7-22. doi:10.1080/00223980.2011.589414

Russell, D., Peplau, L. A., \& Cutrona, C. E. (1980). The Revised UCLA Loneliness Scale: Concurrent and discriminant validity evidence. Journal of Personality and Social Psychology, 39, 472-480. doi:10.1037/0022-3514.39.3.472

Schaefer, E. S. (1965). Children's reports of parental behavior: An inventory. Child Development, 36, 413-424. doi:10.2307/1126465

Scharf, M., Wiseman, H., \& Farah, F. (2011). Parent-adolescent relationships and social adjustment: The case of a collectivistic culture. International Journal of Psychology, 46, 177-190. doi:10.1080/00207594.2010.528424

Soenens, B., Vansteenkiste, M., Goossens, L., Duriez, B., \& Niemiec, C. P. (2008). The intervening role of relational aggression between psychological control and friendship quality. Social Development, 17, 661-681. doi:10.1111/j.1467-9507.2007.00454.x

Sullivan, H. S. (1953). The interpersonal theory of psychiatry. New York, NY: Norton.

Tabachnick, B. G., Fidell, L. S., \& Osterlind, S. J. (2001). Using multivariate statistics (5th ed.). Boston, MA: Pearson Education.

Teppers, E., Klimstra, T. A., Van Damme, C., Luyckx, K., Vanhalst, J., \& Goossens, L. (2013). Personality traits, loneliness, and attitudes towards aloneness in adolescence. 
Journal of Social and Personal Relationships, 30, 1045-1063. doi:10.1177/0265407513481445

Teppers, E., Luyckx, K., Vanhalst, J., Klimstra, T., \& Goossens, L. (2014). Attitudes towards aloneness during adolescence: A person-centred approach. Infant and Child Development, 23, 239-248. doi:10.1002/icd.1856

Vanhalst, J., Goossens, L., Luyckx, K., Scholte, R. H. J., \& Engels, R. C. M. E. (2013). The development of loneliness from mid- to late adolescence: Trajectory classes, personality traits, and psychosocial functioning. Journal of Adolescence, 36, 13051312. doi:10.1016/j.adolescence.2012.04.002

Vanhalst, J., Luyckx, K., \& Goossens, L. (2010, July). A cluster-analytic typology of peerand parent-related loneliness in middle and late adolescence: Cross-sectional and longitudinal associations with psychosocial functioning. Poster presented at the 21th biennial meeting of the International Society for the Study of Behavioural Development (ISSBD), Lusaka, Zambia.

Vanhalst, J., Luyckx, K., \& Goossens, L. (2014). Experiencing loneliness in adolescence: A matter of individual characteristics, negative peer experiences, or both? Social Development, 23, 100-118. doi:10.1111/sode.12019

Vanhalst, J., Luyckx, K., Scholte, R. H., Engels, R. C., \& Goossens, L. (2013). Low selfesteem as a risk factor for loneliness in adolescence: Perceived - but not actual - social acceptance as an underlying mechanism. Journal of Abnormal Child Psychology, 41, 1067-1081. doi:10.1007/s10802-013-9751-y

Vermulst, A. A., \& Gerris, J. R. M. (2005). Quick Big Five Persoonlijkheidsvragenlijst. Handleiding [Quick Big Five Personality Questionnaire. Manual]. Leeuwarden, The Netherlands: LDC. 
Wang, J. M., Rubin, K. H., Laursen, B., Booth-LaForce, C., \& Rose-Krasnor, L. (2013). Preference-for-solitude and adjustment difficulties in early and late adolescence. Journal of Clinical Child and Adolescent Psychology, 42, 834-842. doi:10.1080/15374416.2013.794700

Weiss, R. S. (1973). Loneliness: The experience of emotional and social isolation. Cambridge, MA: MIT Press.

Wichstrøm, L. (1995). Harter's Self-Perception Profile for Adolescents: Reliability, validity, and evaluation of the question format. Journal of Personality Assessment, 65, 100116.

Woodhouse, S. S., Dykas, M. J., \& Cassidy, J. (2012). Loneliness and peer relations in adolescence. Social Development, 21, 273-293. doi:10.1111/j.14679507.2011.00611.x 
Table 1

Descriptive Statistics of and Correlations Among Variables Related with Adolescents' Self-Esteem and Personality (Sample 1)

\begin{tabular}{|c|c|c|c|c|c|c|c|c|c|c|c|c|c|c|c|c|c|c|}
\hline Variable & $M$ & $S D$ & 1 & 2 & 3 & 4 & 5 & 6 & 7 & 8 & 9 & 10 & 11 & 12 & 13 & 14 & 15 & 16 \\
\hline \multicolumn{19}{|l|}{ Loneliness } \\
\hline 1. Parent related loneliness & 1.71 & 0.52 & - & & & & & & & & & & & & & & & \\
\hline 2. Peer related loneliness & 1.62 & 0.48 & $.20^{* *}$ & - & & & & & & & & & & & & & & \\
\hline 3. Aversion to being alone & 2.63 & 0.41 & -.07 & .10 & - & & & & & & & & & & & & & \\
\hline 4. Affinity for being alone & 2.59 & 0.48 & $.20^{* *}$ & $.42 * * *$ & $-.14 *$ & - & & & & & & & & & & & & \\
\hline \multicolumn{19}{|l|}{ Self-esteem } \\
\hline 5. Global self-esteem & 2.93 & 0.61 & $-.35^{* * *}$ & $-.46^{* * *}$ & $-.13 *$ & $-.28 * * *$ & - & & & & & & & & & & & \\
\hline 6. Scholastic competence & 2.75 & 0.51 & $-.18^{* *}$ & $-.20 * *$ & .04 & $-.14^{*}$ & $.37 * * *$ & - & & & & & & & & & & \\
\hline 7. Social competence & 2.97 & 0.50 & $-.20 * *$ & $-.65^{* * *}$ & $.15^{*}$ & $-.31 * * *$ & $.46^{* * *}$ & $.25 * * *$ & - & & & & & & & & & \\
\hline 8. Athletic competence & 2.48 & 0.86 & -.08 & $-.30 * * *$ & .03 & $-.26 * * *$ & $.24 * * *$ & .12 & $.43 * * *$ & - & & & & & & & & \\
\hline 9. Physical appearance & 2.61 & 0.64 & $-.29 * * *$ & $-.32 * * *$ & -.11 & -.11 & $.69 * * *$ & $.26 * * *$ & $.42 * * *$ & $.34 * * *$ & - & & & & & & & \\
\hline 10. Romantic appeal & 2.59 & 0.52 & -.09 & $-.40^{* * *}$ & .10 & $-.14^{*}$ & $.37 * * *$ & $.20 * *$ & $.57 * * *$ & $.38 * * *$ & $.48 * * *$ & - & & & & & & \\
\hline 11. Behavioral conduct & 2.67 & 0.45 & $-.29 * * *$ & -.09 & -.11 & -.02 & $.35 * * *$ & $.27 * * *$ & .08 & .00 & $.15^{*}$ & -.10 & - & & & & & \\
\hline 12. Close friendship & 3.11 & 0.54 & -.15 & $-.66^{* * *}$ & $.18^{* *}$ & $-.39^{* * *}$ & $.36^{* * *}$ & $.21^{* * *}$ & $.58^{* * *}$ & $.29 * * *$ & $.27 * * *$ & $.39 * * *$ & .03 & - & & & & \\
\hline \multicolumn{19}{|l|}{ Personality } \\
\hline 13. Agreeableness & 5.43 & 0.65 & $-.18 * *$ & $-.15^{*}$ & $.23 * * *$ & -.12 & .12 & .06 & $.36 * * *$ & .10 & .08 & $.14^{*}$ & $.13^{*}$ & $.27 * * *$ & - & & & \\
\hline 14. Conscientiousness & 3.93 & 1.29 & $-.27 * * *$ & .03 & -.01 & -.03 & -.01 & .06 & .10 & .07 & .01 & -.04 & $.30 * * *$ & -.08 & $.17 * *$ & - & & \\
\hline 15. Extraversion & 4.64 & 1.27 & $-.17 * *$ & $-.51^{* * *}$ & .09 & $-.34 * * *$ & $.36^{* * *}$ & $.31 * * *$ & $.67 * * *$ & $.30 * * *$ & $.26^{* * *}$ & $.46 * * *$ & -.09 & $.43 * * *$ & $.19 * *$ & -.06 & - & \\
\hline 16. Emotional stability & 3.80 & 1.05 & -.12 & $-.34 * * *$ & $-.17 * *$ & $-.20 * *$ & $.43 * * *$ & $.31 * * *$ & $.26 * * *$ & $.20 * *$ & $.39 * * *$ & $.23^{* * *}$ & $.23 * * *$ & $.25^{* * *}$ & -.07 & -.10 & $.36^{* * * *}$ & - \\
\hline 17. Openness to experience & 4.59 & 0.92 & .03 & -.02 & $-.15^{*}$ & $.18^{* *}$ & $.16^{*}$ & $.13^{*}$ & .07 & -.01 & $.19 * *$ & $.17 * *$ & -.09 & .07 & .09 & -.07 & $.13^{*}$ & .07 \\
\hline
\end{tabular}
$* p<.05 . * * p<.01 . * * * p<.001$. 
Table 2

Descriptive Statistics of and Correlations Among Variables Related with Parental Responsiveness and Psychological Control (Sample 2)

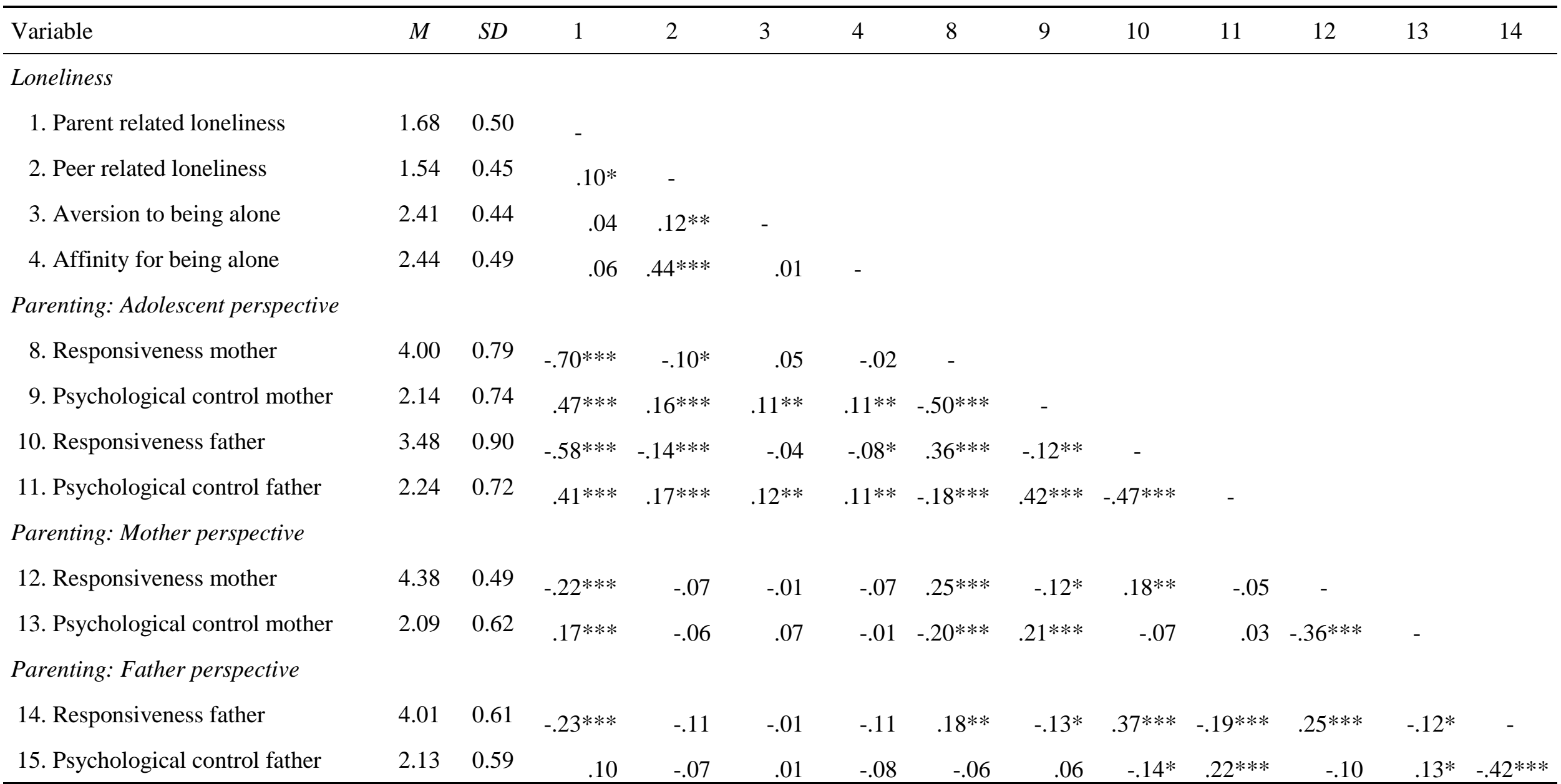

$* p<.05 . * * p<.01 . * * * p<.001$. 
Table 3

Descriptive Statistics of and Correlations Among Variables Related with Adolescent's Peer Group Functioning and Friendships (Sample 3)

\begin{tabular}{|c|c|c|c|c|c|c|c|c|c|c|c|c|c|c|}
\hline Variable & $M$ & $S D$ & 1 & 2 & 3 & 4 & 5 & 6 & 7 & 8 & 9 & 10 & 11 & 12 \\
\hline \multicolumn{15}{|l|}{ Loneliness } \\
\hline 1. Parent related loneliness & 1.76 & 0.56 & - & & & & & & & & & & & \\
\hline 2. Peer related loneliness & 1.64 & 0.51 & $.19 * * *$ & - & & & & & & & & & & \\
\hline 3. Aversion to being alone & 2.49 & 0.47 & $.15^{* * *}$ & $.14 * * *$ & - & & & & & & & & & \\
\hline 4. Affinity for being alone & 2.49 & 0.52 & $.16^{* * *}$ & $.40 * * *$ & .03 & - & & & & & & & & \\
\hline \multicolumn{15}{|l|}{ Peer nominations } \\
\hline 5. Likability & 0.06 & 0.98 & -.04 & $-.20 * * *$ & $.10 * *$ & -.06 & - & & & & & & & \\
\hline 6. Dislikability & -0.02 & 0.97 & .05 & $.18 * * *$ & $-.08 *$ & .03 & $-.45 * * *$ & - & & & & & & \\
\hline 7. Shyness & 0.00 & 0.97 & $-.08 *$ & $.28 * * *$ & $-.08 *$ & $.11 * *$ & $-.35 * * *$ & $.29 * * *$ & - & & & & & \\
\hline 8. Aggression & -0.03 & 0.95 & $.13 * * *$ & -.05 & -.03 & -.04 & $-.09 * *$ & $.27 * * *$ & $-.18 * * *$ & - & & & & \\
\hline 9. Victimization & -0.01 & 0.98 & -.01 & $.25 * * *$ & $-.08 *$ & .06 & $-.34 * * *$ & $.55 * * *$ & $.32 * * *$ & .04 & - & & & \\
\hline 10. Bullying & -0.04 & 0.94 & $.12 * * *$ & $-.13 * * *$ & -.03 & -.05 & -.04 & $.28 * * *$ & $-.19 * * *$ & $.63 * * *$ & -.03 & - & & \\
\hline \multicolumn{15}{|l|}{ Friendships } \\
\hline 11. Friendship quantity & 2.01 & 1.36 & $-.09 * *$ & $-.25 * * *$ & $.12 * * *$ & $-.11 * *$ & $.52 * * *$ & $-.31 * * *$ & $-.23 * * *$ & $-.07 *$ & $-.24 * * *$ & .01 & - & \\
\hline 12. Negative quality & 2.24 & 0.75 & $.15 * * *$ & $.18 * * *$ & .05 & $.19 * * *$ & .00 & -.03 & -.05 & .03 & -.03 & .01 & -.04 & - \\
\hline 13. Positive quality & 4.20 & 0.51 & $-.10 * *$ & $-.33 * * *$ & $.18 * * *$ & $-.16 * * *$ & $.14 * * *$ & $-.10 * *$ & $-.15 * * *$ & -.01 & $-.13 * * *$ & -.02 & $.12 * * *$ & $-.24 * * *$ \\
\hline
\end{tabular}

$* p<.05 . * * p<.01 . * * * p<.001$. 
Table 4

Univariate ANOVAs and Post-hoc Cluster Comparisons Based on Tukey HSD Tests (Sample 1)

\begin{tabular}{|c|c|c|c|c|c|c|c|c|c|c|c|c|c|c|c|c|}
\hline \multirow[b]{2}{*}{ Variable } & \multicolumn{2}{|c|}{ Indifference } & \multicolumn{2}{|c|}{ Moderate } & \multicolumn{2}{|c|}{ Negative attitude } & \multicolumn{2}{|c|}{$\begin{array}{c}\text { Loneliness } \\
\text { parents }\end{array}$} & \multicolumn{3}{|c|}{$\begin{array}{c}\text { Loneliness } \\
\text { peers }\end{array}$} & \multicolumn{3}{|c|}{ Positive attitude } & \multirow[b]{2}{*}{$F(5,235)$} & \multirow[b]{2}{*}{$\eta^{2}$} \\
\hline & Mean & (SD) & Mean & (SD) & Mean & (SD) & Mean & (SD) & Mea & & (SD) & Mea & an ( & (SD) & & \\
\hline \multicolumn{17}{|l|}{ Self-esteem } \\
\hline Global self-esteem & $3.32^{\mathrm{c}}$ & $(0.42)$ & $2.96^{\mathrm{b}, \mathrm{c}}$ & $(0.58)$ & $3.05^{\mathrm{b}, \mathrm{c}}$ & $(0.49)$ & $2.87^{\mathrm{a}, \mathrm{b}}$ & $(0.56)$ & 2.52 & a & $(0.58)$ & 2.61 & $\mathrm{a} \quad($ & $(0.67)$ & $13.23 * * *$ & 0.22 \\
\hline Scholastic competence & $2.81^{\mathrm{b}}$ & $(0.56)$ & $2.81 \mathrm{a,b}$ & $(0.39)$ & $2.87 \mathrm{~b}$ & $(0.44)$ & $2.81 \quad \mathrm{a}, \mathrm{b}$ & $(0.46)$ & 2.58 & $\mathrm{a}, \mathrm{b}$ & $(0.52)$ & 2.58 & a $\quad($ & $(0.63)$ & $2.52 *$ & 0.05 \\
\hline Social competence & $3.19^{\mathrm{b}}$ & $(0.40)$ & $3.06^{\mathrm{b}}$ & $(0.35)$ & $3.21 \mathrm{~b}$ & $(0.34)$ & $3.23 \mathrm{~b}$ & $(0.36)$ & 2.45 & a & $(0.44)$ & 2.64 & a $\quad($ & $(0.55)$ & $25.75^{* * *}$ & 0.35 \\
\hline Athletic competence & $2.77 \mathrm{~b}$ & $(0.78)$ & 2.38 a,b & $(0.90)$ & $2.71 \mathrm{~b}$ & $(0.83)$ & $2.61 \mathrm{~b}$ & $(0.79)$ & 2.06 & a & $(0.82)$ & 2.20 & a $\quad($ & $(0.82)$ & $5.11 * * *$ & 0.10 \\
\hline Physical appearance & $2.97 \mathrm{~b}$ & $(0.51)$ & $2.60^{\mathrm{a}, \mathrm{b}}$ & $(0.53)$ & $2.66^{\mathrm{a}, \mathrm{b}}$ & $(0.63)$ & $2.44^{\mathrm{a}}$ & $(0.79)$ & 2.41 & a & $(0.62)$ & 2.31 & a $\quad($ & $(0.70)$ & $6.80^{* * *}$ & 0.13 \\
\hline Romantic appeal & $2.69^{\mathrm{b}}$ & $(0.48)$ & $2.61 \mathrm{~b}$ & $(0.47)$ & $2.75^{\mathrm{b}}$ & $(0.45)$ & $2.80^{\mathrm{b}}$ & $(0.58)$ & 2.26 & a & $(0.47)$ & 2.39 & $\mathrm{a}, \mathrm{b}$ & $(0.55)$ & $6.99 * * *$ & 0.13 \\
\hline Behavioral conduct & 2.78 & $(0.50)$ & 2.70 & $(0.46)$ & 2.65 & $(0.42)$ & 2.47 & $(0.45)$ & 2.72 & & $(0.41)$ & 2.55 & & $(0.42)$ & 2.07 & 0.04 \\
\hline Close friendship & $3.34^{\mathrm{b}}$ & $(0.43)$ & $3.19^{\mathrm{b}}$ & $(0.32)$ & $3.31 \mathrm{~b}$ & $(0.39)$ & $3.50^{\mathrm{b}}$ & $(0.29)$ & 2.61 & a & $(0.49)$ & 2.64 & a $\quad($ & $(0.63)$ & $25.98 * * *$ & 0.36 \\
\hline \multicolumn{17}{|l|}{ Personality } \\
\hline Agreeableness & $5.51 \mathrm{a,b}$ & $(0.67)$ & 5.51 b & $(0.56)$ & $5.60^{\mathrm{a}, \mathrm{b}}$ & $(0.56)$ & $5.60^{\mathrm{a}, \mathrm{b}}$ & $(0.77)$ & 5.31 & $\mathrm{a}, \mathrm{b}$ & (0.64) & 5.04 & a $\quad($ & $(0.63)$ & $4.12 * *$ & 0.08 \\
\hline Conscientiousness & $4.15^{\mathrm{b}}$ & $(1.36)$ & $4.31 \mathrm{~b}$ & $(1.18)$ & $3.88^{\mathrm{a}, \mathrm{b}}$ & $(1.27)$ & $3.19^{\mathrm{a}}$ & $(1.48)$ & 4.03 & b & (1.11) & 3.52 & - & (1.25) & $3.31 * *$ & 0.07 \\
\hline Extraversion & $5.06^{\mathrm{c}, \mathrm{d}}$ & $(1.33)$ & $4.55 \mathrm{~b}, \mathrm{c}$ & $(0.95)$ & $5.33 \mathrm{~d}$ & $(0.79)$ & $5.20^{\mathrm{c}, \mathrm{d}}$ & $(0.93)$ & 3.64 & a & (1.11) & 3.95 & $\mathrm{a}, \mathrm{b}$ & $(1.41)$ & $14.80^{* * *}$ & 0.24 \\
\hline Emotional stability & $4.16^{\mathrm{b}}$ & $(0.91)$ & $3.65^{\mathrm{a}, \mathrm{b}}$ & $(0.99)$ & $4.02 \mathrm{~b}$ & $(1.05)$ & $3.85^{\mathrm{a}, \mathrm{b}}$ & $(1.08)$ & 3.23 & a & $(0.98)$ & 3.69 & $\mathrm{a}, \mathrm{b}$ & (1.16) & $4.64 * * *$ & 0.09 \\
\hline Openness to experience & 4.60 & $(0.89)$ & 4.57 & $(0.92)$ & 4.41 & $(0.81)$ & 4.45 & $(1.03)$ & 4.66 & & $(0.91)$ & 4.82 & & (1.07) & 0.89 & 0.02 \\
\hline
\end{tabular}

Note. Means are significantly different if they do not have a same superscript. A mean without a superscript is not significantly different from any other mean.

$* p<.05 . * * p<.01 . * * * p<.001$. 
Table 5

Univariate ANOVAs and Post-hoc Cluster Comparisons Based on Tukey HSD Tests (Sample 2)

\begin{tabular}{|c|c|c|c|c|c|c|c|c|c|c|c|c|c|c|}
\hline \multirow[b]{2}{*}{ Parenting } & \multicolumn{2}{|c|}{ Indifference } & \multicolumn{2}{|c|}{ Moderate } & \multicolumn{2}{|c|}{$\begin{array}{c}\text { Negative } \\
\text { attitude }\end{array}$} & \multicolumn{2}{|c|}{$\begin{array}{c}\text { Loneliness } \\
\text { parents }\end{array}$} & \multicolumn{2}{|c|}{$\begin{array}{c}\begin{array}{c}\text { Loneliness } \\
\text { peers }\end{array} \\
\end{array}$} & \multicolumn{2}{|c|}{$\begin{array}{c}\text { Positive } \\
\text { attitude }\end{array}$} & \multirow[b]{2}{*}{$\begin{array}{l}F(5, \\
287)\end{array}$} & \multirow[b]{2}{*}{$\eta^{2}$} \\
\hline & Mean & $(\mathrm{SD})$ & Mean & (SD) & Mean & (SD) & Mean & $(\mathrm{SD})$ & Mean & (SD) & Mean & (SD) & & \\
\hline Responsiveness mother & $4.21^{\mathrm{c}}$ & $(0.62)$ & $4.24^{\mathrm{c}}$ & $(0.47)$ & $4.42^{\mathrm{c}}$ & $(0.43)$ & 3.28 a & $(0.68)$ & $3.85 \mathrm{~b}$ & $(0.64)$ & $4.35^{\mathrm{c}}$ & $(0.51)$ & $24.62 * * *$ & 0.30 \\
\hline Psychological control mother & $1.83^{\mathrm{a}}$ & $(0.68)$ & $2.09^{\mathrm{a}}$ & $(0.66)$ & $1.83^{\mathrm{a}}$ & $(0.57)$ & $2.66^{b}$ & $(0.83)$ & $2.23^{\mathrm{a}}$ & $(0.78)$ & $1.86^{\mathrm{a}}$ & $(0.55)$ & $10.47 * * *$ & 0.15 \\
\hline Psychological control father & $1.95^{\mathrm{a}}$ & $(0.67)$ & $2.01 \mathrm{a,b}$ & $(0.55)$ & $2.01 \mathrm{a}, \mathrm{b}$ & $(0.68)$ & $2.66^{\mathrm{c}}$ & $(0.85)$ & $2.35^{\mathrm{b}, \mathrm{c}}$ & $(0.69)$ & $1.96^{\mathrm{a}, \mathrm{b}}$ & $(0.56)$ & $8.43 * * *$ & 0.13 \\
\hline \multicolumn{15}{|l|}{ Mother perspective } \\
\hline Responsiveness mother & 4.45 & $(0.44)$ & 4.37 & $(0.41)$ & 4.40 & $(0.48)$ & 4.22 & $(0.59)$ & 4.32 & $(0.48)$ & 4.42 & $(0.59)$ & 1.33 & 0.02 \\
\hline Psychological control mother & 2.13 & $(0.55)$ & 2.26 & $(0.68)$ & 2.01 & $(0.62)$ & 2.27 & $(0.57)$ & 1.95 & $(0.47)$ & 1.95 & $(0.74)$ & $2.54^{*}$ & 0.04 \\
\hline
\end{tabular}

Note. Means are significantly different if they do not have a same superscript. A mean without a superscript is not significantly different from any other mean.

$* p<.05 . * * p<.01 . * * * p<.001$. 
Table 6

Univariate ANOVAs and Post-hoc Cluster Comparisons Based on Tukey HSD Tests (Sample 3)

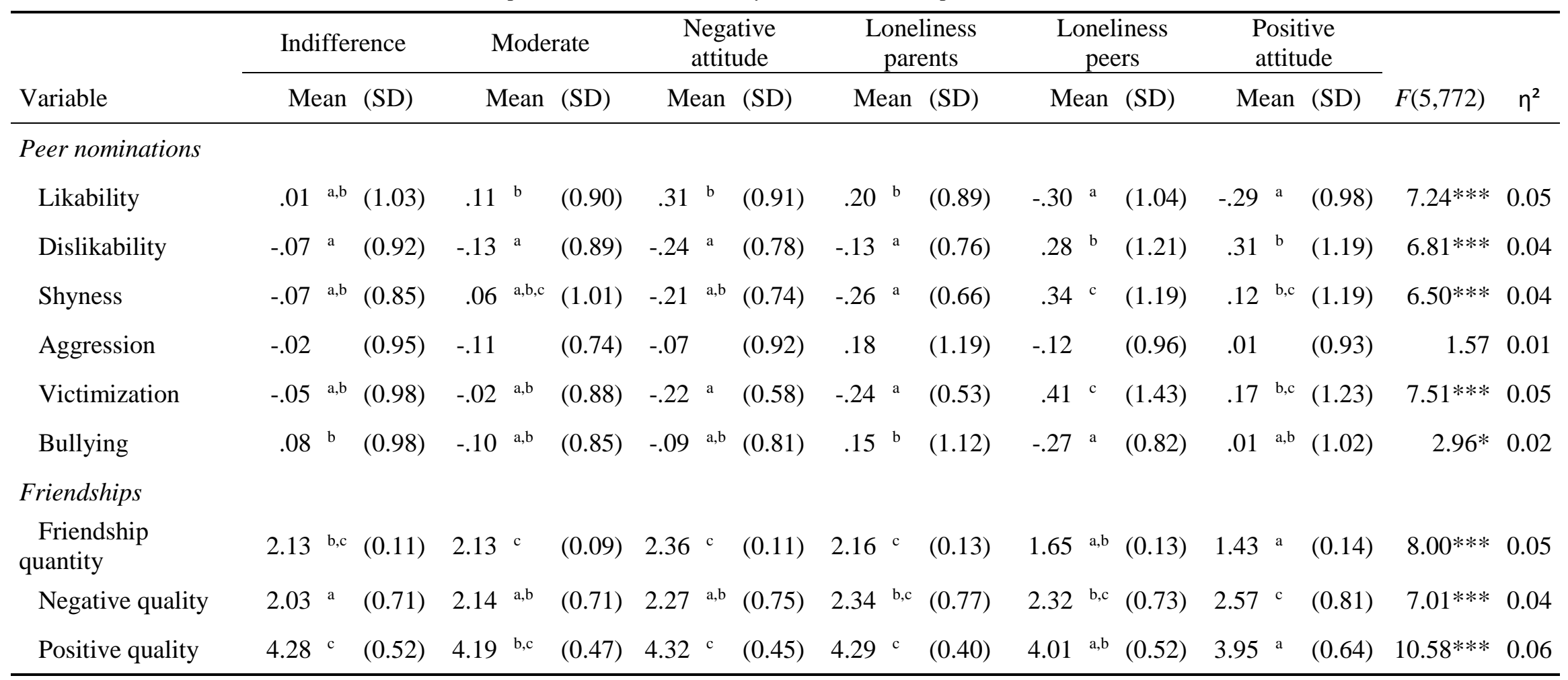

Note. Means are significantly different if they do not have a same superscript. A mean without a superscript is not significantly different from any other mean.

$* p<.05 . * * p<.01 . * * * p<.001$. 

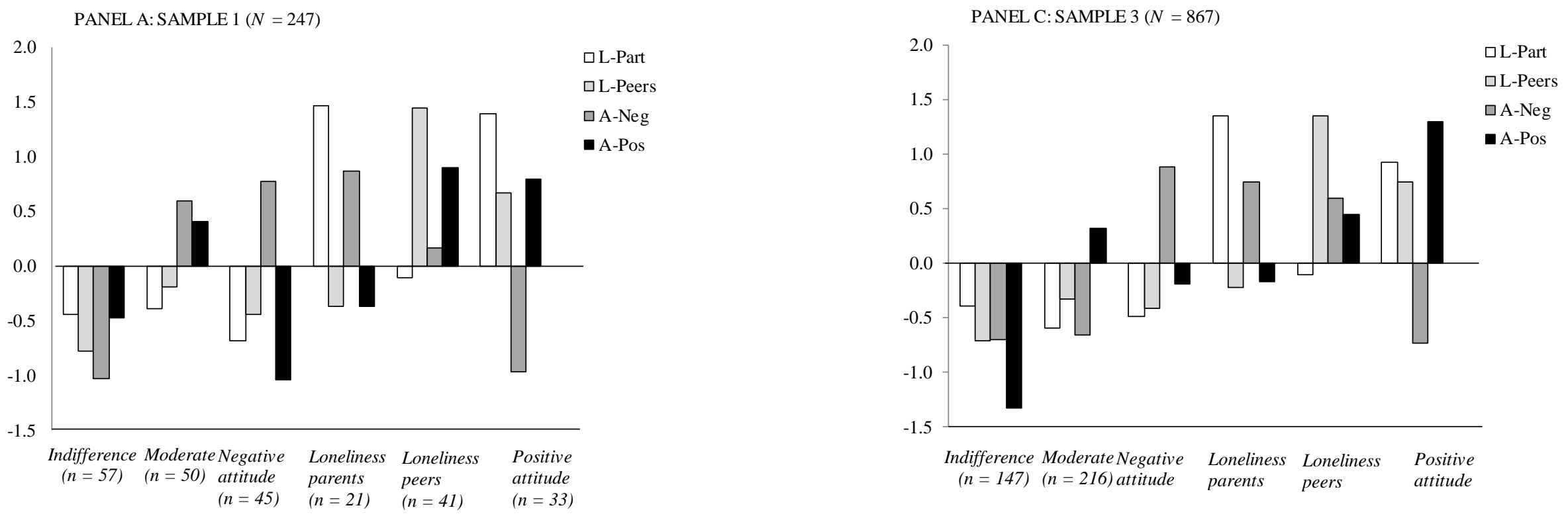

PANEL B: SAMPLE $2(N=613)$
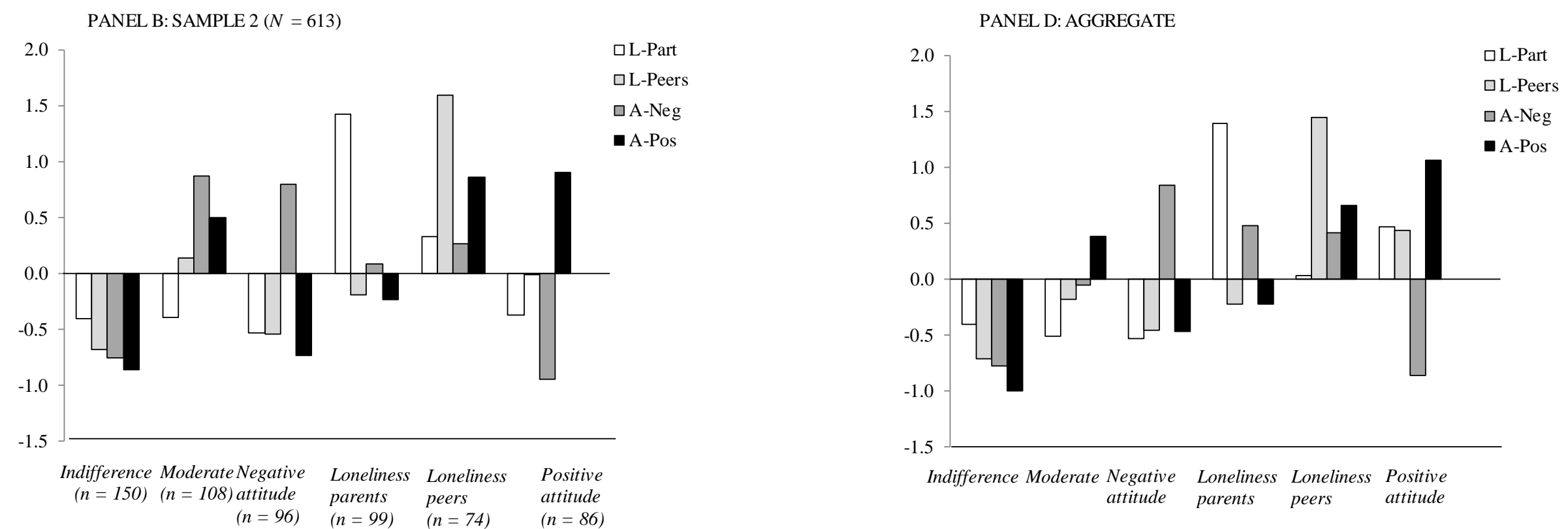

Figure 1. Final six-cluster solution based on Z-scores for parent-related loneliness (L-Part), peer-related loneliness (L-Peers), aversion to being alone (A-Neg), and affinity for being alone (A-Pos). Panels A to C represent cluster solutions of the three individual samples; Panel D represents an overall cluster solution. 